clinical diseases by, for example, immunosuppressive treatment. A similar situation may exist for warts. Immune reactions are certainly important in this connection, but they are evidently not the only regulating factors. Metabolic changes or regulation at the cellular level may be of importance in these viral diseases. ${ }^{13} 22$

In the present study an inverse correlation between the occurrence of warts and rheumatoid factor was found. Rheumatoid factor can enhance and amplify neutralisation of herpes virus antibodies in the presence of complement. ${ }^{24}$ Similarly, rheumatoid factor might help resistance to wart virus in vivo. This suggests that rheumatoid factor should be considered as an active factor in immune reactions against viral infections.

This study was supported in part by a grant from the Sigrid Jusélius Foundation to Professor Kari Penttinen and a grant from the Finnish Cultural Foundation. The expert technical help of Miss Helena Kainulainen, Mrs Anja Kallionpää, and Miss Kirsi-Marja Pylkkänen is gratefully acknowledged.

\section{References}

1 Staples, P J, et al, Arthritis and Rheumatism, 1974, 17, 1.

2 Dubois, E L (editor), Lupus Erythematosus. Los Angeles, University of Southern California Press, 1974.
${ }^{3}$ Denman, A M, Medical Biology, 1975, 53, 61.

Cohen, A S, et al, Bulletin on the Rheumatic Diseases, 1971, 21, 643.

5 Johansson, E A, Lassus, A, and Salo, O P, Acta Dermatovenereology, 1972, 52, 196.

${ }^{6}$ Pyrhönen, S, and Penttinen, K, Lancet, 1972, 2, 1330.

7 Tuffanelli, D L, Archives of Dermatology, 1972, 106, 553.

8 Roberts, S O B, in Textbook of Dermatology, ed A Rook, D S Wilkinson, and F J G Ebling, p 1908. Oxford, Blackwell, 1972.

${ }^{9}$ Spencer, E S, and Andersen, H K, British Medical fournal, 1970, 3, 251.

${ }^{10}$ Morison, W L, British Fournal of Dermatology, 1975, 92, 625.

11 Shelley, W B, Acta Dermatovenereology, 1972, 52, 33.

12 Brodersen, I, Genner, J, and Brodthagen, H, Acta Dermatovenereology, $1974,54,291$.

13 Allison, A C, Transplantation Reviews, 1974, 19, 3.

${ }^{14}$ Messner, R P, Lindström, F D, and Williams, R C, jun, fournal of Clinical Investigation, 1973, 52, 3046.

15 Stobo, J D, and Loehnen, C P, Mayo Clinic Proceedings, 1976, 51, 479.

${ }_{16}$ Horwitz, D A, Arthritis and Rheumatism, 1972, 15, 353.

17 Hahn, B H, Bagby, M K, and Osterland, C K, The American fournal of Medicine, 1973, 55, 25.

18 Schneider, J, et al, Clinical and Experimental Immunology, 1975, 20, 187.

19 Butler, W T, et al, Arthritis and Rheumatism, 1972, 15, 231.

${ }^{20}$ Rosenthal, C J, and Franklin, E C, Arthritis and Rheumatism, 1975, 18, 207.

${ }^{21}$ Baum, J, and Ziff, M, fournal of Clinical Investigation, 1969, 48, 758.

22 Pyrhönen, S, and Johansson, E A, Lancet, 1975, 1, 592.

${ }^{23}$ Kalliomäki, J L, and Halonen, P, Annals of the Rheumatic Diseases, 1972, 31, 192.

${ }^{24}$ Ashe, W K, et al, Science, 1971, 172, 176.

(Accepted 8 November 1976)

\title{
Atenolol, methyldopa, and chlorthalidone in moderate hypertension
}

\author{
J WEBSTER， T A JEFFERS， D B GALLOWAY， J C PETRIE， N P BARKER
}

British Medical fournal, 1977, 1, 76-78

\section{Summary}

Combined treatment with low doses of different drugs is widely used for moderate hypertension. The effects of atenolol and methyldopa at two dose levels and in combination at the lower doses were studied in patients with moderate hypertension on continuous treatment with chlorthalidone. The mean reduction in standing blood pressures obtained with atenolol 150 and $300 \mathrm{mg} /$ day was about $27 / 17 \mathrm{~mm} \mathrm{Hg}$ and with methyldopa 750 and $1500 \mathrm{mg} /$ day about $28 / 14 \mathrm{~mm} \mathrm{Hg}$. Combined treatment with atenolol $150 \mathrm{mg} /$ day and methyldopa $750 \mathrm{mg} / \mathrm{day}$ for four weeks resulted in a reduction of $38 / 25 \mathrm{~mm} \mathrm{Hg}$. No difference was observed between the effects of the two doses of atenolol or between the two doses of methyldopa. The lower dose of atenolol was better than the lower dose of methyldopa in reducing lying and standing diastolic blood pressures.

These findings show that in patients on continuous treatment with chlorthalidone the addition of atenolol

\footnotetext{
Department of Therapeutics and Clinical Pharmacology, University of Aberdeen AB9 2ZD

J WEBSTER, MRCP, lecturer

T A JEFFERS, MRCP, lecturer

D B GALLOWAY, MRCP, lecture

J C PETRIE, MRCP, senior lecturer

Imperial Chemical Industries, Macclesfield, Cheshire

N P BARKER, statistician
}

alone or methyldopa alone or of atenolol and methyldopa in combination is effective in the treatment of moderate hypertension.

\section{Introduction}

Methyldopa and diuretics such as chlorthalidone are widely used to treat moderate hypertension. Atenolol is a new cardioselective $\beta$-adrenoceptor antagonist, which is an effective hypotensive agent. No within-patient studies have been carried out to assess the effect of combined treatment with atenolol and methyldopa. We report the findings of a study to assess the hypotensive effects of atenolol and methyldopa alone and in combination in a group of outpatients with moderate hypertension on chlorthalidone treatment.

\section{Patients and methods}

In the procedure we followed patients were invited to participate in the outpatient trial if their morning lying diastolic pressures were over $105 \mathrm{~mm} \mathrm{Hg}$ and under $125 \mathrm{~mm} \mathrm{Hg}$ and all other outpatient and ward blood pressures confirmed persistent increases in blood pressure. ${ }^{1}$ The nature of the trial was explained and all gave their consent.

After discharge from hospital the patients were seen at the hypertension clinic within two weeks. The protocol excluded patients whose lying diastolic blood pressures fell below $100 \mathrm{~mm} \mathrm{Hg}$ after a four-week outpatient run-in period on chlorthalidone treatment and placebo. One $25-\mathrm{mg}$ tablet of chlorthalidone was taken (Hygroton-K-Geigy) in the morning during the run-in period and throughout the study. After the run-in period a double-blind crossover method was used to assess the effects on lying, standing, and post-exercise blood pressure of three treatments, each provided by two identical-looking tablets 
given three times a day. The treatments were: $(a)$ atenolol $150 \mathrm{mg} /$ day for two weeks increasing to $300 \mathrm{mg} /$ day for a further two weeks; (b) methyldopa $750 \mathrm{mg}$ /day for two weeks increasing to $1500 \mathrm{mg} /$ day for a further two weeks; and (c) atenolol $150 \mathrm{mg} /$ day and methyldopa $750 \mathrm{mg} /$ day for four weeks.

Each treatment was given for four weeks and the treatment periods were separated by a four-week "washout" period on chlorthalidone alone and placebo. Patients were given their drug supplies in three containers ( $\mathrm{A}, \mathrm{B}$, and $\mathrm{C}$ ), and were instructed to take one tablet from containers A and B three times daily $(0800,1500$, and 2200 ) and one tablet (always chlorthalidone) from container C. During the run-in period and the washout periods all $\mathrm{A}$ and $\mathrm{B}$ tablets contained placebo tablets that looked identical to the atenolol and methyldopa tablets. Two-week supplies of drugs were given to each patient in prepacked and paired containers.

The patients were seen every two weeks, and their blood pressures were recorded using Hawksley random-zero sphygmomanometers under standard conditions at the same time of day, in the same arm, and by the same observers. The mean of two or three blood pressure readings after three to five minutes lying and after two to three minutes standing was recorded. A single reading was taken after the predetermined exercise load specified for each patient had been performed. The diastolic end-point was taken as the phase- 4 muffle. Between-observer comparisons of the blood pressure readings were made at intervals throughout the trial.

The observer not recording the blood pressure completed the questionnaire on symptoms in another room. Separate forms were completed for every patient at each of the 12 visits. Questions included volunteered information in addition to specific items about general wellbeing, dizziness, headache, energy, tiredness, mood, sleep, dreams, chest pain, ankle swelling, dyspnoea, and bowel habit. Tablet counts and body weights were also recorded.

\section{Results}

Fourteen patients (10 men) aged 28-64 years (mean $49 \cdot 8$ years) with a mean initial weight of $78.5 \mathrm{~kg}(59-99 \mathrm{~kg})$ completed the trial Tablet counts were satisfactory throughout $(>90 \%)$. Four additional patients were withdrawn from the trial. Two patients on chlorthalidone developed severe and symptomatic postural hypotension on the lower dose of each drug (standing pressures $67 / 53 \mathrm{~mm} \mathrm{Hg}$ on atenolol and $60 /$ ? $\mathrm{mm} \mathrm{Hg}$ on methyldopa). In two other patients lying diastolic blood pressures fell below $100 \mathrm{~mm} \mathrm{Hg}$ after the run-in period on treatment with chlorthalidone alone.

Mean values for blood pressure and pulse during the different periods of the trial are shown for the 14 patients in table 1 and figs 1 and 2 . The mean initial lying and standing blood pressures were 181/ $120 \mathrm{~mm} \mathrm{Hg}$ and $172 / 122 \mathrm{~mm} \mathrm{Hg}$ respectively. After the one month run-in period on chlorthalidone the blood pressure levels had fallen to $164 / 111 \mathrm{~mm} \mathrm{Hg}$ and $155 / 111 \mathrm{~mm} \mathrm{Hg}$ respectively $(\mathbf{P}<0.05)$.

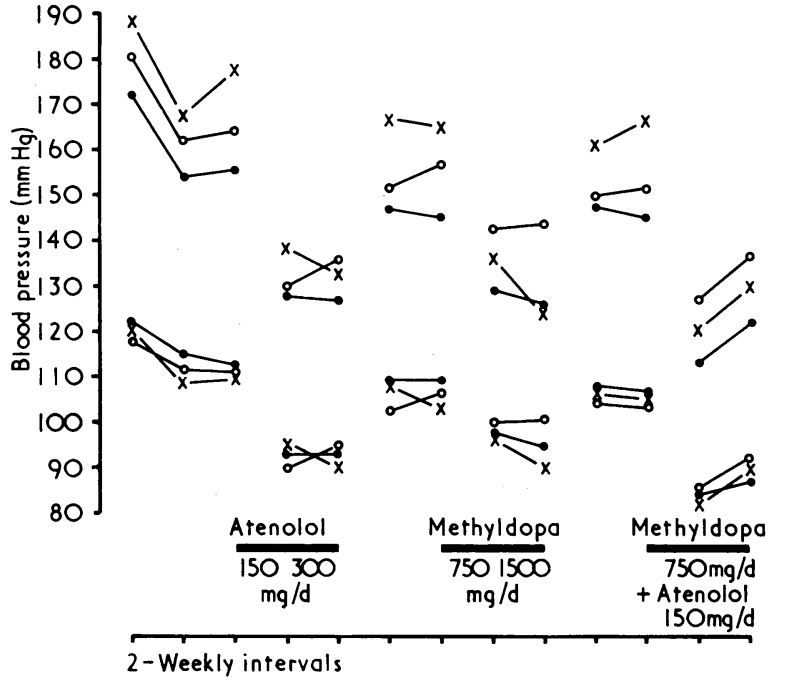

FIG 1-Mean blood pressures during run-in and treatment periods. $O=$ Lying. $=$ Standing. $\times=$ Post exercise.

The mean reduction in standing blood pressure levels in patients treated with atenolol 150 and $300 \mathrm{mg} /$ day was $27 / 17 \mathrm{~mm} \mathrm{Hg}$ and $28 / 17 \mathrm{~mm} \mathrm{Hg}$ respectively. The mean reductions in standing blood pressure levels obtained with methyldopa 750 and $1500 \mathrm{mg}$ /day were $26 / 13 \mathrm{~mm} \mathrm{Hg}$ and $30 / 16 \mathrm{~mm} \mathrm{Hg}$ respectively, and with combined treatment about $38 / 24 \mathrm{~mm} \mathrm{Hg}$.

The comparison of treatments showed that atenolol $150 \mathrm{mg} /$ day was better than methyldopa $750 \mathrm{mg} /$ day in reducing lying systolic $(P<0.05)$ and diastolic $(P<0.01)$ and standing diastolic $(P<0.05)$ blood pressures. After two weeks of treatment atenolol $150 \mathrm{mg} /$ day combined with methyldopa $750 \mathrm{mg} /$ day was better than atenolol $150 \mathrm{mg} /$ day in reducing standing $(P<0.01)$ and postexercise $(P<0.001)$ systolic pressures and lying $(P<0.05)$, standing $(P<0.01)$, and postexercise $(\mathbf{P}<0.001)$ diastolic levels. No difference in the reduction of blood pressures was evident between the effects of 150 and 300 $\mathrm{mg} /$ day of atenolol. No difference was observed between the effects of 750 and $1500 \mathrm{mg} /$ day of methyldopa or between atenolol $300 \mathrm{mg} /$ day and methyldopa $1500 \mathrm{mg} /$ day. After four weeks' treatment the effect on blood pressure of combined treatment with atenolol and methyldopa was no better than that produced by atenolol $300 \mathrm{mg} /$ day but was better than that produced by methyldopa $1500 \mathrm{mg} /$ day in reducing lying and standing diastolic blood pressure levels $(P<0.05)$. Comparison of the effect of combined therapy after two and four weeks of treament showed no significant differences except for a rise in standing systolic blood pressure.

Mean $( \pm S E)$ blood pressures, pulse rates, and weight during run-in and treatment periods in 14 patients on continuous chlorthalidone treatment

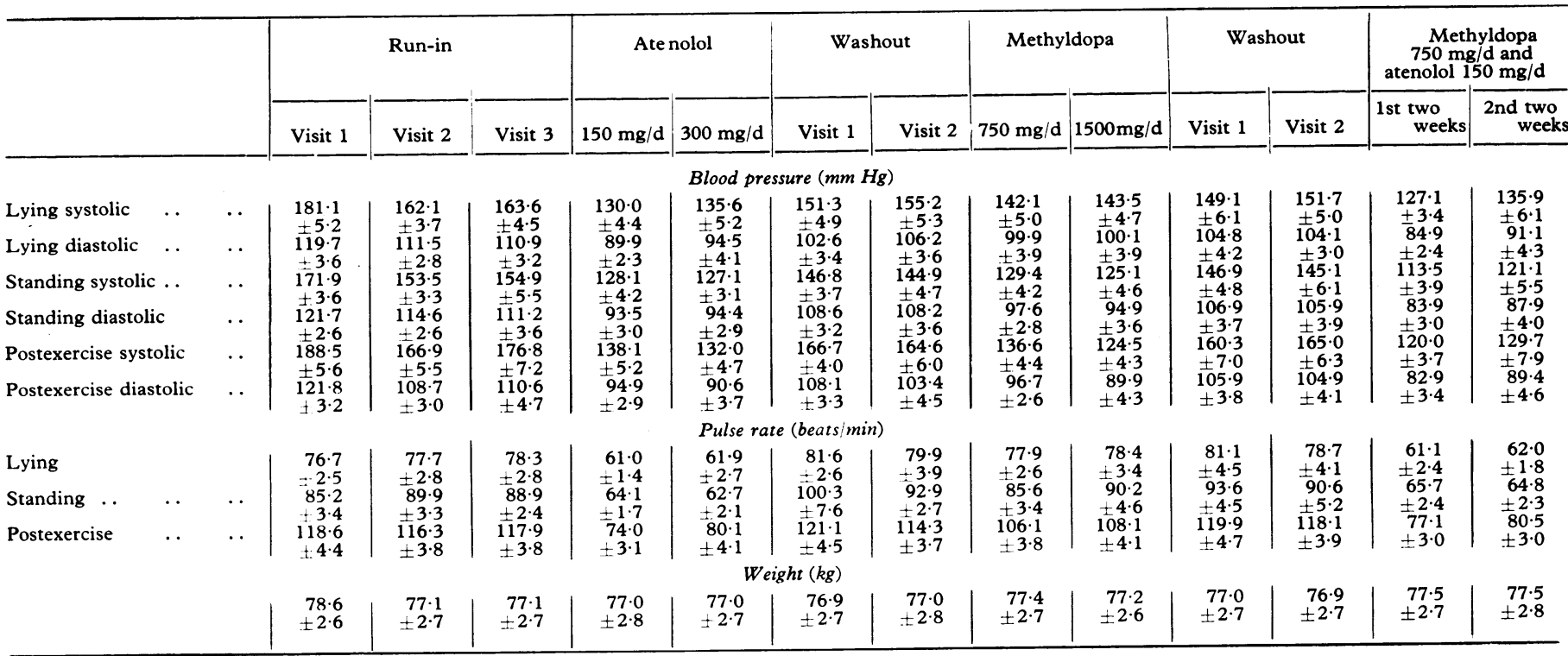




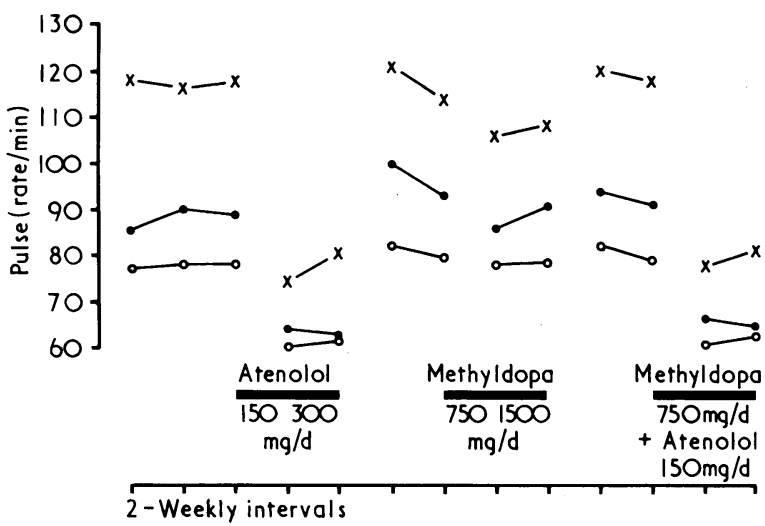

FIG 2-Mean pulse rate during run-in and treatment periods. $\mathrm{O}=$ Lying. $\mathbf{O}=$ Standing. $\mathrm{x}=$ Post exercise.

The pulse rates during the atenolol treatment were all significantly lower than those during the methyldopa or non-atenolol periods $(\mathrm{P}<0.001)$.

Analysis of the questionnaire on side effects showed that the periods of treatment that incorporated methyldopa could be identified. More patients complained of dreams, increased sleeping, increased tiredness, and reduced energy after four weeks of treatment with methyldopa than during the three periods of treatment with chlorthalidone alone or the one period on atenolol alone.

\section{Discussion}

In patients with moderate hypertension on continuous treatment with chlorthalidone the addition of atenolol, methyldopa, or low doses of atenolol and methyldopa in combination is effective in reducing blood pressure. The fall in blood pressure with the addition of atenolol $150 \mathrm{mg} /$ day was greater than that with methyldopa $750 \mathrm{mg} /$ day.
The doses of atenolol chosen for study were adequate. In other studies we have shown that atenolol 50,100, and $200 \mathrm{mg}$ once daily ${ }^{2}$ or atenolol $200-400 \mathrm{mg} /$ day, or in combination with bendrofluazide in twice daily doses, ${ }^{3}$ reduces raised blood pressures. In both these studies an increase in dose above the lowest dose did not further reduce mean blood pressure levels. This finding has been confirmed in the present study. Doubling the dose of methyldopa from 750 to $1500 \mathrm{mg} /$ day did not increase the hypotensive effect significantly. This confirms the findings of Barritt et $a l^{4}$ and of Scott et al (personal communication).

The design of the study incorporated a run-in period and washout periods on chlorthalidone. The diuretic was included because in a previous study in a similar group of patients a period of treatment with placebo alone was included ${ }^{1}$ and the mean levels of lying blood pressure during that placebo period were high-183/114 mm Hg (phase-4). Although we took the precaution of using a background diuretic we now believe that a lower initial dose of atenolol or methyldopa should have been used, because two patients on chlorthalidone had to be withdrawn from the study because of severe and symptomatic hypotension when the lower dose of each drug was added.

We thank all who helped in this study, particularly Mrs B Reid and Mrs M C Smith, and Dr W T Simpson and Mr J A Lewis of Imperial Chemical Industries Limited.

\section{References}

${ }^{1}$ Petrie, J C, et al, British Medical fournal, 1976, 2, 137.

2 Jeffers, T A, et al, British fournal of Clinical Pharmacology, 1977. In press.

3 Petrie, J C, et al, British Medical fournal, 1975, 4, 133.

${ }^{4}$ Barritt, D W, Marshall, A J, and Heaton, S, Lancet, 1976, 1, 503.

\title{
Rate of reversal of hypercalcaemia and hypercalciuria induced by vitamin $\mathrm{D}$ and its $1 \alpha$-hydroxylated derivatives
}

\author{
J A KANIS, R G G RUSSELL
}

British Medical fournal, 1977, 1, 78-81

\section{Summary}

The rate of reversal of hypercalcaemia or hypercalciuria induced by calciferol, dihydrotachysterol, 1- $\alpha$-hydroxycholecalciferol (1- $\left.\alpha-\mathrm{OHD}_{3}\right)$, or 1- $\alpha, 25$-dihydroxycholecalciferol $\left(1-\alpha, 25-(\mathrm{OH})_{2} \mathrm{D}_{3}\right)$ was measured in three normal subjects, two patients with osteoporosis, and 14 patients with disorders resistant to vitamin $D$. The half time for reversal after stopping $1-\alpha, 25(\mathrm{OH})_{2} D_{3}$ was less than that

Renal Unit, Churchill Hospital, and Metabolic Unit, Nuffield Orthopaedic Centre, Oxford

J A KANIS, MRCP, Wellcome senior clinical research fellow

Department of Chemical Pathology, University of Sheffield, Sheffield

R G G RUSSELL, PHD, MRCP, senior lecturer after stopping 1- $\alpha-\mathrm{OHD}_{3}$, calciferol, or dihydrotachysterol. The differences observed were independent of the dose given or length of treatment. When 1- $\alpha-\mathrm{OHD}_{3}$ or $1-\alpha-25-(\mathrm{OH})_{2} D_{3}$ was stopped patients with vitamin $D$ resistant states (hypoparathyroidism, renal tubular hypophosphataemia, or chronic renal failure) showed less rapid reversal of hypercalcaemia and hypercalciuria than did normal subjects. These studies show one potential advantage of $1-\alpha-25-(\mathrm{OH})_{2} D_{3}$ over vitamin $D$, and possibly over $1-\alpha-\mathrm{OHD}_{3}$, in the management of vitamin $D$ resistant states.

\section{Introduction}

Since the discovery that vitamin $\mathrm{D}_{3}$ (cholecalciferol) is converted in the kidney to 1- $\alpha, 25$-dihydroxycholecalciferol $(1-\alpha-25-$ $(\mathrm{OH})_{2} \mathrm{D}_{3}$ ) before exerting its biological effects, ${ }^{1}$ there has been considerable interest in the potential advantages of using $1-\alpha, 25-(\mathrm{OH})_{2} \mathrm{D}_{3}$ or its synthetic analogue, 1- $\alpha$-hydroxycholecalciferol $\left(1-x-\mathrm{OHD}_{3}\right)$, for treating disorders resistant to 